\title{
Luanne Metz: Canadian Leader in Neurology
}

\author{
Parichita Choudhury
}

Keywords: Neurology - Education, Clinical Trails, Inflammatory Diseases, Multiple Sclerosis, Residency Training

doi:10.1017/cjn.2019.245

Can J Neurol Sci. 2019; 46: 621-622

The Canadian Leaders in Neurology series is an initiative of the Canadian Neurological Society whose objective is to showcase exceptional accomplishments by Canadian neurologists who are leaders in their respective fields. In this follow-up segment of the series, Dr. Parichita Choudhury, a neurology resident at University of Calgary, interviews Dr. Luanne Metz, the second recipient of this distinction (Figure 1).

Dr. Metz is a clinical neurologist at the University of Calgary. Dr. Metz is recognized globally in the area of multiple sclerosis (MS). Dr. Metz led a Canada-wide (12 MS clinics) phase III clinical trial which showed in patients with clinically isolated syndrome minocycline decreases risk of conversion to MS, the results of which were published in New England Journal of Medicine. She has led over 50 industry sponsored trials, pioneer in the development of the Calgary MS clinic, and implemented an electronic health record in the MS clinic in Calgary. In 2015, Dr. Metz was awarded the Alberta Medal of Distinguished Service - which recognizes physicians who have made an outstanding personal contribution to the medical profession and to the people of Alberta. She is completing a 5-year term as the section chief of the Department of Clinical Neurosciences at the University of Calgary.

Dr. Metz, firstly congratulations on the great success story of minocycline! Please tell us a bit about the blood, sweat, and tears behind this success.

Certainly, there have been hurdles all along the way. It is really hard to get funding for clinical trials, particularly as you move onto higher phases and they become more expensive. The first hurdle came after the first crossover trial. I had submitted a grant to the Canadian MS Society for minocycline in Secondary Progressive MS which was declined and did not have good reviews. As we finally moved onto phase III trial, we got funding on our second submission, but for a maximum of 3 years. Recruitment was very slow (not slower than other trials) and extensions had to be asked for every year and there was a fair bit of resistance from the scientific advisory committee. So, in a way, this was the "miracle baby" in that we were allowed to continue and finish the trial. To top it all off, getting a positive result was fabulous because you are focusing on getting the job done and hoping for a good outcome.

Do you have advice for young clinician-scientists starting out in their career on how to see their vision through?

You have to take the long route. Expect that at least $50 \%$ of your grants are not going to get funded and do not be too devastated when that happens. Celebrate the little victories: when you do get funding or after you submit; I go shopping (laughs)! After the initial disappointment, think about what the comments are and even if you disagree with many of the comments, see what you can take out of the comments and make your vision better. Do not give up on it. Expect that research takes a LONG time. It is not something you can just dabble in.

I also think it is important to be working on several projects at once, and so that one of them not happening is not going to make your whole research plan fall apart. Hope that all your grants do not come through at the same time because then you have a different kind of problem (laughs)!

A newspaper article I read said almost each line on your Curriculum Vitae features the word MS. Tell us about your path into MS.

My main reasons for going into the field of MS were threefold. I really liked the patients. I identified with the people who had MS: they were my age. At the time I started in MS, there were no disease-modifying therapies available. Really what you could do was manage their symptoms and help them by understanding their disease. I felt that that was such a personal thing that I could and wanted to do. It was something that allowed the specialty of neurology to have the feature of family medicine of long-term contact with patients which was important to me. I also saw that there was no end to the number of questions that could and should be asked in this field. So that was also of great interest to me.

A good friend of my mother's was diagnosed with MS. She was trained as a nurse and was a flight attendant. This was a long time ago. Knowing someone like her with an exciting life and career and to witness what MS did to her was something that stuck with me.

Was there anyone earlier on in your career that you were inspired by or mentored you?

I was very much inspired by Dr. Peter Seland, who was the MS director in Calgary and started the Calgary MS clinic. His way of managing patients inspired me. I was also inspired by the

From the Department of Clinical Neurosciences, University of Calgary, Calgary, Alberta, Canada

Received June 21, 2019. Final Revisions Submitted July 9, 2019. Date of ACCEPTANCE July 12, 2019.

Correspondence to: Parichita Choudhury, Department of Clinical Neurosciences, University of Calgary, 1403-29th Street NW, 12th Floor Foothills Hospital, Calgary, Alberta, Canada. Email: parichita@gmail.com 


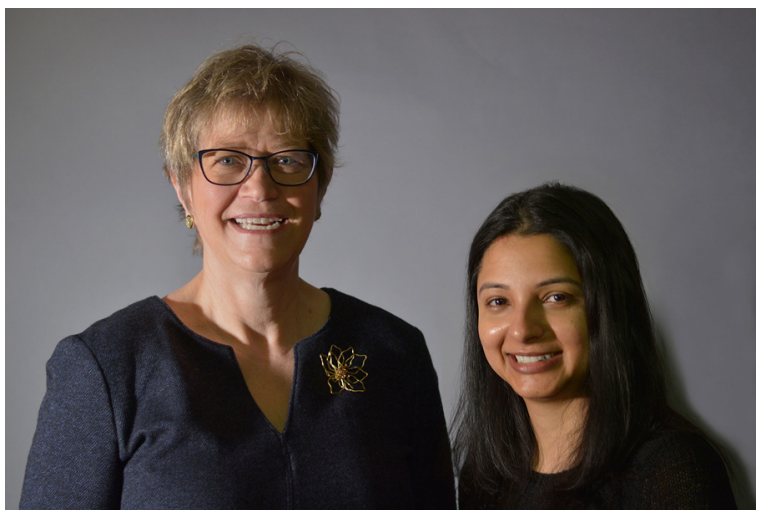

Figure 1: Dr. Luanne Metz (left), with Dr. Parichita Choudhury (right), neurology resident, who conducted the interview.

nurse in the clinic, who was very generous and skilled in dealing with patients. She is now our nurse practitioner and clinic manager. She has been there all along but when I was the resident, she inspired me to stick in this field.

When you took over as the director of MS clinic there were four neurologists, now it operates from two sites and has over a dozen neurologists - please tell us about your role as MS clinic director.

I have always been very passionate about improving care and MS is where I got started. Originally, the MS clinic was meant to be following a small cohort of patients to better understand the disease and slowly became the place for more advanced patients, who required extra time and support. When I took over the clinic, I felt that the patients could get a better experience if they were managed in one central place with all the resources. So, I invited the community neurologists to be part of the clinic. That was the beginning of developing the core where it would provide care for all patients with MS in Calgary. I was able to work with Colleen, our clinic nurse practitioner, and many others to improve the resources and services.

I believe in the Nike slogan "There Is No Finish Line": what should we do next? It includes having ideas that often have to be a bit innovative because there was not really a clinic like ours anywhere but it also requires the same patience as doing research. Just like your research grant would not get funded, your requests and arguments for more resources can take several years before you eventually get it. As long as you make your case based on evidence, numbers, and data, you will get there!

You were awarded the Young Women Christian Association Woman of Distinction Award. Did you have any female role models yourself?

I did not appreciate the importance to young women of having female role models until I became the division head. Before that I did not think this was anything out of the ordinary and that comes from the fact that my role models have been my mother, my grandmother, and my great grandmother. I come from a line of women doing things and being in charge. My mother was a lawyer and Queen's Counsel, who led the southern Alberta review panel for 30 years. My grandmother was a nurse who, at the age of 14, during World War I wanted to become an ambulance driver! They sent her back because they figured out she was underage but she was a very good driver (chuckles). She then went onto nursing and was the matron of a hospital in Saskatchewan. Her mother had her own business in California, so who would think there was a reason you would not do something because you are a woman when you come from that background. I saw discrimination, but I did not think it was a barrier to me. But I did not realize so many other young women did not have that experience.

What is the one thing you have learnt as a mentor since you have been in this role.

I think the main thing is - people need encouragement to do the best they can do. I think a mentor can really help you do amazing things in your pathway that you did not realize you could just via positive message.

\section{What do you like to do when you are not at work?}

I like to spend time with family. We play a lot of board games and cards. My favorite card game is Canasta. We have a fairly competitive card playing family.

\section{What is your favorite vacation destination?}

Maui is my favorite vacation place.

If your current self could give your 20-year-old self a piece of advice, what would that be?

I would do exactly the same things as I have done. I am very lucky! I did not plan everything and it kind of fell into place.

\section{ACKNOWLedgements}

The Canadian Leaders Segment is conceptualized by the Canadian Neurological Society. The author would like to thank Dr. Luanne Metz for participating in the series and Drs. Adil Harroud, Jodie Burton and Fiona Costello for feedback on the article.

\section{Disclosures}

Dr. PC is the resident representative for the Canadian Neurological Society which conceptualized the Canadian Leaders in Neurology series. 